\title{
ACCIÓN CULTURAL MUNICIPAL E NOVAS TECNOLOXÍAS
}

Lois Andrade

Bonaval Multimedia S.L.

Tense dito de xeito reiterado que a sociedade da información constitúe o maior factor de cambio que se coñece actualmente no noso planeta e que está presente no conxunto das actividades sociais. Grazas principalmente a uns enormes progresos científicos e tecnolóxicos desenvoltos cunha intensidade xeracional excepcional, contemplamos como esas ferramentas de automatización de datos e procesos, os ordenadores, invadiron o noso espazo de traballo. A súa fame de almacenamento xerou decontado novos soportes de información. Eran os soportes ópticos: os CD primeiro, nos xogos e na música, axiña os DVD no cine, etc. que invadiron o quiosco e entraron nos fogares ao mesmo tempo que o ordenador persoal.

A conectividade incorporouse a este proceso e xerou un espazo que de forma autoexpansiva comezou a modelar a organización da actividade humana; internet, na procura de información, e os usos lúdicos das TIC introduciron cambios inéditos nas novas relacións co coñecemento e coa cultura. Paseniñamente, o e-mail no traballo fíxose imprescindible, a telefonía móbil algo universal e internet un fenómeno que medra exponencialmente conectando a través de redes de comunicacións os espazos máis diversos nun proceso de mundialización.

O diálogo entre dispositivos e a súa conexión a través de redes deron lugar ao que se deu en chamar converxencia tecnolóxica. Os ordenadores, os lectores ópticos, as PDA e os teléfonos móbiles tencionan formar un contorno único que incorpora múltiples formas de presentar e/ou acceder á información. Un contorno ao que non é alleo a TV interactiva e que amosa que as novas tecnoloxías da información e da comunicación (TIC) non son só trebellos e coberturas dispoñibles, senón tamén a tecnoloxía social e organizativa. 


\section{A DIVERSIDADE CULTURAL: LUCES E SOMBRAS}

Deste xeito, non se pode deixar de pensar que as TIC poden ser unha excelente ferramenta para o desenvolvemento cultural e social e que, grazas aos enormes progresos científicos e tecnolóxicos que a acompañan, a globalización representa unha fonte de oportunidades sen precedentes. En efecto, o desenvolvemento das novas tecnoloxías da información e a apertura crecente dos mercados ofrecen novas perspectivas de progreso susceptibles de contribuír á creación e evolución de novas formas de intercambio no plano económico e cultural. A chamada sociedade do coñecemento permite a creación de formas inéditas de interacción e cooperación entre os individuos, as comunidades e as culturas, e atopamos unha dispoñibilidade crecente de todas as formas de expresión, que posibilitan un intercambio xeneralizado.

Non obstante, a diversificación non exclúe necesariamente un certo tipo de uniformización. Asistimos non tanto a unha restrición da variedade, senón máis ben á polarización da función social das tecnoloxías e a unha redución de matices e diferenzas que se están a converter en marxinais.

Unha referencia inescusable témola en internet, que é un medio difícil de regular e cunha capacidade de almacenamento case infinita pero que, pola contra, establece desigualdades no idioma e na distribución dos contidos. Resulta difícil reducir disparidades e impulsar unha tecnoloxía que poida servir os cidadáns para loitar contra a pobreza cando o idioma predominante nun $70 \%$ é o inglés e esta lingua é a única en múltiples contidos de tipo científico, ou se na información priman como mediadores os grandes operadores internacionais.

Desde a periferia e no ámbito dunha cultura minoritaria como a nosa, este feito preocúpanos especialmente e introduce unha variable nova na reflexión sobre o que se dá en chamar fenda dixital.

Sería interesante poder dispor dun marco comparativo do noso posicionamento na relación entre TIC e culturas minoritarias, pero non é doado. O que si podemos dicir é que unha ollada 
superficial do noso contorno máis inmediato constata que a situación de Galicia ao respecto presenta múltiples axentes dignos de mención, en campos tan diversos como os portais lingüísticos, a recollida de documentación gráfica ou os GIS locais, moitos deles presentes nestas xornadas. E que, o mesmo que noutras culturas que están a sufrir unha situación parecida, asistimos ao paradoxo de que a diversidade que penaliza -o idioma- é en si mesmo un elemento de dinamización social e institucional.

Tal feito pon de manifesto que as máis das veces esquecemos o rol positivo da comunidade como xerador de novas prácticas e as posibilidades das TIC como instrumento de inclusión comunitaria.

Porén, o carácter relativamente illado destas experiencias tende a espallar a idea dunha certa utopía no uso das tecnoloxías, feito moi acusado na comunidade educativa: a instalación da crenza de que a dispoñibilidade xenérica das tecnoloxías na sociedade abre as fiestras dunha vida mellor. Esta concepción entende que a eficacia e as vantaxes que outorgan as tecnoloxías comportan, en si mesmas, un cambio cultural e unha mellora das condicións económicas e, deste modo, un desenvolvemento da sociedade.

O problema é que así entendidas as tecnoloxías pasan a ser interpretadas como un fenómeno externo ás culturas e ás sociedades ás que se pretende transformar, e temos unha visión reducionista do problema centrada no acceso que permite a translación absoluta da responsabilidade da implantación das TIC ás institucións de máis alto rango e aos operadores de telecomunicación.

\section{A FENDA DIXITAL: O CASO DE GALICIA}

Resulta obvio que o acceso ás novas tecnoloxías é un problema de primeira orde en Galicia. Segundo datos do INE de 2003, os fogares galegos con dispoñibilidade de internet son un $16 \%$, fronte ao $25 \%$ español e ao $45 \%$ europeo. Cómpre sinalar que este diferencial acurtouse en 2004 e que neste mesmo ano houbo un intenso proceso de implantación de telecentros no rural. 
Pero o elemento de análise máis significativo é que temos unha baixa taxa de penetración da banda ancha, que reduce a funcionalidade de internet, e unha nova fenda no tocante á distribución entre os núcleos rurais e urbanos: o nivel de introdución de ordenadores persoais nos núcleos urbanos duplica o dos núcleos rurais e a porcentaxe de fogares conectados a internet no medio urbano case triplica a do rural, segundo un estudo da Consellaría de Cultura do ano 2003.

Así, o termo «fenda dixital» abrangue non soamente a diferenza entre os individuos senón tamén entre familias, grupos sociais, empresas, localidades e áreas xeográficas que posúen ou non a oportunidade de acceder ás tecnoloxías da información e da comunicación (TIC) e utilizalas eficientemente creando oportunidades para o futuro.

Por outro lado, a fenda non remite unicamente ao acceso, senón tamén ao uso e aproveitamento das vantaxes das TIC. Dado que o informacional está a se converter nun piar da sociedade e da economía, a fenda dixital implica que aqueles non informatizados e formados nas TIC non teñen, por poñer un exemplo, a opción de participar en estratexias de goberno electrónico, de formación en liña e mesmo en empregos, pois cada vez son máis os traballos que precisan eses coñecementos. Como podemos ver, a fenda dixital menoscaba dereitos tan importantes como a representación, as liberdades, a educación ou o traballo.

Este problema é teimosamente invocado desde moitas voces e foros, pero a verdade é que carecemos de solucións operativas que permitan resolver o gap cada vez máis importante entre capas sociais e entre territorios. Quizais para resolvelo se teñan que asignar recursos importantes para converter a dispoñibilidade dun ordenador por parte do usuario nun problema político de estado. En moitos países desenvoltos o auténtico cambio cultural chegou coa dispoñibilidade dun ordenador portátil e posiblemente a universalización do acceso funcional a internet sexa algo imprescindible. Pero a teima tamén é outra: podemos facer algo antes? Podemos facelo nós? 


\section{O IMPULSO LOCAL}

Paralelamente, a medida que a globalización avanza, observamos unha tendencia cara ao local cuxos efectos poden ser positivos á hora de favorecer a implantación das TIC. As manifestacións locais son espontáneas, diversas e maioritariamente de tipo presencial. Abranguen publicacións electrónicas, de localidades e grupos, e nos últimos tempos invaden o espazo dos servizos: os servizos de información local, as experiencias de e-administración, a promoción dos destinos turísticos e a televenda de entradas, por poñer un exemplo de comercio electrónico, permiten albiscar en ámbitos diversos cómo o contorno local é un espazo social onde esta aspiración á implantación das TIC se fai máis expresa e visible. Trátase dun fenómeno basicamente urbano e que en moitos dos casos presupón unha escala que exclúe as pequenas poboacións, pero que sinala un potencial camiño para seguir.

Non se trataría, neste caso, de asumir acriticamente as tecnoloxías, facéndolle o xogo á globalización no sentido de deseñar modelos homoxéneos, senón máis ben de aproveitar as vantaxes da autonomía local para, desde a periferia, dar acubillo a unha apropiación crítica das tecnoloxías, formulando proxectos locais cunha clara vocación de servizo público. O que compre é indagar no gap local e propoñer ideas e estratexias metodolóxicas anovadoras, pero, sobre todo, dar soporte ao espazo local mediante o uso das tecnoloxías e implicar as TICs nos procesos de aprendizaxe.

Temos que ser conscientes -é un imperativo ético- que a incorporación das TIC á sociedade é un proceso que se constrúe colectivamente. A xestión participada das solucións locais de e-administración e e-servizos non debe considerarse como un estado vencellado a imperativos de orde técnica, senón como un proceso que se constrúe. É dicir, a implantación das TIC soamente pode considerarse sustentable se os actores locais adquiren unha serie de capacidades e se dotan de potenciais técnicos e sociais que permitan á sociedade local asumir novas perspectivas. Proceso que debe ser respectuoso cos grupos que compoñen a sociedade local xa 
que deben conservar a súa autonomía e ampliar a súa eficacia e a súa identidade.

Por ese motivo, resulta importante a aparición e o coñecemento de boas prácticas e casos de éxito que animen aos axentes sociais e ás institucións a tomar iniciativas nesta dirección, feito que ten máis que ver co impulso de estratexias de comunicación que favorezan a participación e inviten á imaxinación que co almacenamento e difusión da información. Do mesmo xeito, cómpre indicar que a procura de modelos de pequena escala é, dada a nosa configuración territorial e social, algo imprescindible.

Estas experiencias modestas e orzamentariamente accesibles existen en diversos formatos e, ao meu entender, presentan certos elementos comúns:

- Reflexionan sobre o gap local e tentan palialo con solucións imaxinativas e de baixo custo.

- Procuran instrumentos que se beneficien da converxencia tecnolóxica e integran diferentes plataformas e servizos: internet, correo, ftp, ás veces móbiles.

- Utilizan como elemento de oportunidade o contorno GNU e o soft libre.

- Son maioritariamente proxectos de rede e desenvolven a súa actividade nos chamados contornos cliente servidor.

- Presentan múltiples perfís de usuario e diversifican a súa actividade.

- Son funcionais, intuitivos e a súa interface é amable.

- Incorporan procesos e/ou mecanismos de sensibilización, divulgación e formación en relación cos mellores usos da tecnoloxía dispoñible. 